\title{
COMUNICAÇÃO INTERNA E SUA IMPORTÂNCIA NAS ORGANIZAÇÕES: CASE PETROBRAS. ${ }^{1}$
}

\author{
Karina Felício Silva ${ }^{2}$, Roberto Mancuzo Júnior ${ }^{3}$ \\ Universidade do Oeste Paulista - UNOESTE. ${ }^{2}$ Pós-graduação em Gestão em Marketing e Comunicação. ${ }^{3}$ Curso de \\ Comunicação Social, Presidente Prudente - SP. E-mail: mancuzo@unoeste.br
}

\section{RESUMO}

O presente artigo visa expor a importância e a necessidade da comunicação interna hoje em dia nas empresas. A proposta ilustra os pontos determinantes, os canais de comunicação, para que desta forma seja bem elaborada e com eficácia na sua realização. Tendo em vista que o mundo está globalizado e que a tecnologia está em alta, as empresas estão se adequando de uma nova forma para que os colaboradores fiquem sempre bem informados e sejam os embaixadores da marca. Como exemplo de uma comunicação interna bem elaborada houve a análise de um Case da PETROBRAS, vencedor do prêmio Aberje 2011.

Palavras-Chaves: Comunicação. Comunicação Interna. Canais de Comunicação. Tecnologia e colaboradores. PETROBRAS.

\begin{abstract}
This article aims to explain the importance and the need for internal communication in business today. The proposal illustrates the decisive points, channels of communication, so this way is well designed and effectively in their realization. Given that the world is globalized, technology is on the rise, companies are adapting to a new way for developers to always stay informed and be the brand ambassadors. As an example of an elaborate internal communication was the analysis of a Case of PETROBRAS, winner of the 2011 Aberje.
\end{abstract}

Key Words: Communication. Internal Communication. Channels of Communication. Technology and employees. PETROBRAS.

\footnotetext{
${ }^{1}$ Pesquisa elaborada em estudos pormenorizados na disciplina de Comunicação Empresarial de especialização em Gestão em Marketing e Comunicação da PÓS UNOESTE.
} 


\section{INTRODUÇÃO}

A comunicação não para. Em todo ambiente onde há pessoas elas se comunicam de uma forma ou de outra, direta ou indiretamente, sempre usando algum meio para esse processo se concluir, havendo sempre a interação e o diálogo de duas ou mais pessoas, próximas ou distantes, seja de maneira formal ou informal.

Nos últimos tempos, dentro das organizações foi surgindo à necessidade do controle da comunicação existente, o que tem exigido dos executivos e empresários, muito mais atenção sobre o assunto. Percebe-se então, que é indispensável o estudo da comunicação dentro das organizações, por se tratar de um tema extenso e complexo. No âmbito das organizações existem vários meios que resultam em fracasso ou mesmo numa reação - fazendo com que os esforços em se comunicar acabem tendo um efeito contrário dentro da empresa.

Desta forma, o estudo deste tema é essencial, apontando pontos positivos e negativos e analisando o processo de comunicação utilizado, tem o intuito de torná-las empresas com comunicação eficaz, possibilitando sua colocação de maneira estratégica no mercado.

\section{METODOLOGIA}

Para realização desta pesquisa e que foi de extrema importância para a obtenção dos objetivos, foi à coleta de dados através de um estudo bibliográfico ou de informações já existentes. Conforme Lakatos e Marconi (1985, p. 22) comentam a pesquisa bibliográfica é aquela realizada em artigos, livros e publicações, os quais proporcionam várias informações válidas de fatos ocorridos, através de fontes seguras e concretas sobre o assunto.

Também esta pesquisa coletou dados por meio do estudo de caso que de acordo com Gil (1994), trata-se de um estudo profundo e exaustivo de um ou poucos objetos, de maneira que permita seu extenso e detalhado conhecimento. Desta forma, o estudo de caso, baseia-se na coleta de informações através de um estudo profundo e extenuante, onde detalhes proporcionam conhecimento sobre o objeto ou o caso estudado. Neste artigo apresento os dados do case da PETROBRAS, vencedora do prêmio Aberje 2011.

\section{DEFINIÇÃO DE COMUNICAÇÃO}

Desde os tempos mais antigos, a necessidade de se comunicar é questão de sobrevivência. Quando éramos bebês e não sabíamos falar, o choro vinha como forma de comunicação e expressão, para chamar atenção. Comunicação então é o processo de transmitir informação a uma 
pessoa, e espera-se a compreensão da mensagem, pois se não houver compreensão, também não houve comunicação.

A seguir verifica-se diversas definições de comunicação afim de ampliar nossos horizontes como diferentes pensamentos e ideias, ponto de vista, conceito, reflexão sobre o tema em questão.

Segundo Chiavenato (2000, p.142): “a comunicação é a troca de informações entre indivíduos". Significa tornar comum uma mensagem ou informação.

Para Pimenta (2002) a palavra comunicação é relevante quando uma ideia é feita em comum, sendo assim, se um indivíduo concluir sua mensagem de forma que seja captada e entendida por outros indivíduos, então ocorre a ação de comunicar-se.

A comunicação é um instrumento imprescindível para integração, interação, troca mútua e desenvolvimento entre pessoas independente da atividade a ser realizada. O processo de comunicação é subdividido por três partes: Emissor: pessoa que emite uma mensagem ou informação; Mensagem: é a ideia que o emissor deseja comunicar; e Receptor: é a etapa de recepção da mensagem.

Assim, como Bateman e Snell (1998) explicam, o emissor inicia o processo transmitindo a informação ao receptor através de algum canal, tal como um meio verbal ou escrito. O receptor decodifica a mensagem, lendo-a e interpretando-a.

Porém, conforme Gil, (2001, p.73), a análise do processo de comunicação "deixa claro que a comunicação vai além do simples ato de informar. Requer sintonia com o interlocutor e também o esclarecimento por parte deste acerca dos efeitos produzidos pela mensagem", ou seja, é necessário entrosamento entre ambas as partes, emissor e receptor, para que a mensagem seja eficaz.

\section{Comunicação Interna}

A atividade da comunicação interna, faz parte da área da comunicação organizacional e vem se destacando cada vez mais dentro das organizações. Percebe-se que em cenários modernos e tecnológicos não há mais omissão de informação a seus funcionários.

Em tempos que comunicação é primordial para qualquer organização, não basta ter uma equipe de colaboradores talentosa e motivada, é necessário que a equipe esteja bem informada e com integrantes que tenham boa comunicação entre eles e com a organização de forma geral.

Segundo Nassar (2003) a comunicação interna deixa de ser uma atividade secundária para converter em uma importante ferramenta de gestão empresarial, contribuindo para a construção 
da imagem, capacitação profissional e integração, e além disso, conclui que funcionários bem informados são considerados um importante diferencial competitivo.

A comunicação interna é utilizada como instrumento estratégico, de forma que a mensagem seja direcionada no momento oportuno, impulsionado o colaborador a atingir a meta estabelecida, criar sinergia entre os setores de forma que cresça o trabalho cooperativo, priorizar decisões ágeis e corretas, organizar métodos de trabalho mais produtivas motivando as vendas, entre mais.

\section{Fluxos da Comunicação}

Os fluxos da comunicação produzem grande influência sobre a eficiência do processo de comunicação interna. Eles formam os caminhos, os meios, os desvios e os degraus por onde a comunicação se estende. Os fluxos variam de organização para organização.

Segundo Torquato (2010), os fluxos da comunicação interna são subdivididos em quatro dimensões: descendente, ascendente, lateral e diagonal.

- Descendente: os fluxos são de cima para baixo, as comunicações são gerenciais, ou seja, da cúpula para a base. A maior barreira para a comunicação gerencial é reter informações, pois quanto mais informações, maior o poder;

- Ascendente: os fluxos ascendentes são de baixo para cima e tendem a ter uma linguagem informal, são conhecidas também com rádio- peão;

- Lateral: as comunicações laterais são feitas por indivíduos do mesmo nível hierárquico;

- Diagonal: fluxo diagonal trata de mensagem trocada entre superior e subordinado localizado em outro departamento, são contatos menos burocráticos e tem forte valor para programas interdepartamentais, é uma comunicação rápida, informal.

\section{Ruídos}

Dentro da organização, muitas vezes acontecem interrupções da mensagem enviada, pois o processo de comunicação nunca é perfeito, essas interrupções são denominadas como ruídos. Ruído é uma perturbação não desejável em qualquer comunicação, pois isso pode trazer perdas ou desvio de mensagem.

O ruído pode se caracterizar como a "rádio peão", ou seja, mensagens informais que vão passando de boca a boca e sendo alteradas ou até mesmo inventadas pelos próprios indivíduos, e 
devem ser tratados pela diretoria com muita atenção, pois com o desenvolvimento desses rumores provocarão instabilidade e insegurança em tempos de crise.

Segundo Torquato (2010) o rumor atende à necessidade humana, sendo elas: a expectativa e a ansiedade, o indivíduo quer entender o que está acontecendo no seu ambiente, para se assegurar que está livre de ameaças, ou o contrário disso, quando recebe informação que está em perigo, precisa prevenir-se, então a melhor maneira de se resguardar de qualquer eventualidade, é buscar a informação.

\section{CANAIS DE COMUNICAÇÃO}

Os canais de comunicação da organização estão a serviço de sistemas técnicos e funcionais, agindo para utilidade geral como: reforço e eficácia dos programas de segurança e higiene, interação e socialização interna, relacionamento trabalhista, desenvolvimento organizacional, campanhas em geral e relações públicas externas.

O grande desafio é identificar o canal de comunicação mais adequado para a organização, pois envolve a cultura, os costumes, a missão da organização e o perfil dos empregados; então é exigido muita cautela na hora da escolha. Conhecer o público interno e saber como introduzir a comunicação, é talvez a garantia de sucesso do processo de comunicação interna, o cuidado com a linguagem com os meios é fundamental.

Temos como ferramentas neste caso o Mural, Jornal Corporativo, Intranet, e Revista Corporativa. Para Jaques Vigneron: “A comunicação não é tarefa só dos especialistas, ela é assunto de todos e de todos os momentos, desde o staff de direção que determina a política de comunicação até o chão de fábrica."

\section{NOVAS TECNOLOGIAS}

Nos dias atuais a internet se tornou uma grande aliada para as organizações, facilitando o dia a dia das pessoas, no que diz respeito a comunicação.

É impossível você pensar em comunicação sem se lembrar da intranet, do e-mail, dos chats internos, das videoconferências, das redes sociais.

Todos esses mecanismos acima citados facilitam a comunicação interna em grandes empresas. Porém para Jaques Vigneron (2001): “A comunicação não é tarefa só dos especialistas, ela é assunto de todos e de todos os momentos, desde o staff de direção que determina a política de comunicação até o chão da fábrica." 
A nova comunicação tecnológica agrega aos colaboradores a interatividade, pois é possível que eles opinem sobre determinado assunto, sugiram novas idéias para a campanha, e fiquem interados sobre as novidades na organização.

\section{A IMPORTÂNCIA DA COMUNICAÇÃO INTERNA}

A comunicação interna serve para que a empresa envolva todos os funcionários em um bem comum que é o avanço no mercado. Uma empresa só consegue sucesso se todos os envolvidos estiverem motivados pelo mesmo desejo.

Desde os primórdios o homem trabalhava em grupo, e nos dias atuais à realidade não é muito diferente, por mais robotizada que seja a indústria, fábrica ou empresa, sempre há necessidade de um homem para operar e comunicar as pessoas sobre o que está ocorrendo.

Não há cliente melhor que o funcionário, ele deve acreditar na missão da organização, nos valores por ela passados, para que assim consiga trabalhar melhor e produzir mais.

Dentre os objetivos da comunicação interna, se destacam estes como os principais:

- Difundir dentro da empresa os conhecimentos adquiridos pelos empregados, diretores e proprietários;

- Divulgar as ações da empresa de forma direta e transparente;

— Envolver a equipe de trabalho da empresa nas metas da organização.

Sabe-se que o homem tem a necessidade de se comunicar e isso é o que o torna um ser social. Segundo Bordenave (2002), a motivação dos humanos tem duas bases complementares: a afetiva e a instrumental.

Os profissionais devem ser inseridos em todos os aspectos da empresa, são somente no trabalho em que realiza todos os dias.

A comunicação interna serve para informar sobre as mudanças operacionais, resultados da empresa, eventos culturais, treinamentos e até mesmo um espaço para os colaboradores publicarem outras informações de seu interesse.

\section{Case Petrobras}

A Petrobras lançou em 2010 o Projeto "As Cores do Saber a herança que nos faz iguais por meio do conhecimento", que visava ações de conscientização dos empregados e seus dependentes sobre a importância do combate à discriminação racial e o respeito às diferenças. (PETROBRAS, 2011). 
Sabemos que uma das maiores populações negras do planeta é brasileira, e isso faz com que seja necessário gerar uma consciência individual em toda a população do País.

A campanha envolveu equipes da Ouvidoria, da Gerência de Comunicação e Relações Institucionais e da Gerência de Recursos Humanos. O projeto visava combater todas as formas de discriminação, e para isso focaram na Igualdade Racial, e no princípio de respeito às diferenças.

A parceira da Petrobras Distribuidora - BR, com a PETROBRAS e a Secretaria Especial de Políticas de Promoção da Igualdade Racial (SEPPIR) do Governo Federal, gerou um conjunto de três ações principais.

Estas ações envolviam o público interno, seus familiares, parceiros e a sociedade em geral; Todas elas eram voltadas para a divulgação e propagação de conhecimento e educação da cultura negra.

As ações foram as seguintes:

Ação 1 - Público Interno: divulgação Lei 10.639 com entrega de Kits (material didático lúdico) a filhos de empregados, concurso de desenho, redação e projeto multimídia;

Ação 2 - Cadeia de relacionamento: convênio para inserção de módulo de igualdade racial no programa Capacidade Máxima a partir de 2011, com 17 ônibus, e treinamento de cerca de, 72 mil trabalhadores em 775 municípios em todo o país;

Ação 3 - Sociedade em geral: memorando de cooperação com SEPPIR para apoio de criação de rede articulada para implantação de Ouvidoria Permanente da Igualdade Racial.

De acordo com o jornalista integrante da Petrobras, Adriano Val, as ações foram voltadas para todos os públicos:

Decidimos falar aos funcionários e seus familiares, em um exercício de transmissão de conhecimento. Nada menos que dois mil dependentes de funcionários em todo o país receberam kits com material didático que valorizava o legado da herança afro no Brasil e a participação de personalidades negras na construção da identidade e do desenvolvimento do país.

Com este Projeto a Petrobras, ganhou em 2011, um dos mais importantes Prêmios do Jornalismo, o Prêmio Aberje (ABERJE, 2013), na Categoria de Comunicação e Relacionamento com o Público Interno.

Prêmio Aberje: Foi iniciado em 1967, quando ocorreu o primeiro encontro de editores de jornais de empresas, junto com a primeira Exposição de Jornais e Revistas de Empresas. Nesse evento nasce a Aberje e se cria o Prêmio Aberje de Jornalismo Empresarial. 
Seu criador Nilo Luchetti já dizia (ABERJE, 2013): "O comunicador é um interprete objetivo e humano da dinâmica empresarial, que deverá conduzir a harmonização dos interesses de todos que participam das complexas organizações de nossos dias".

\section{CONCLUSÃO}

Para finalizar o estudo, verifica-se que a comunicação é uma ferramenta de grande importância para a organização. Concluí-se que em qualquer organização é necessário o planejamento, desenvolvimento e acompanhamento da comunicação.

A comunicação interna se torna aliada dos empresários fazendo com que os funcionários sejam estimulados e reconhecidos, consequentemente, produzem mais e geram mais lucro para as organizações.

Uma organização que faz bom uso da comunicação interna está na frente no mercado de trabalho, se destacando e ganhando sucesso.

\section{REFERÊNCIAS}

BATEMAN, T. S.; SNELL, S. A. Administração - Construindo Vantagem Competitiva. São Paulo: Atlas, 1998.

BORDENAVE, Juan E. Día. O que é comunicação. São Paulo: Brasiliense,1991.

CHIAVENATO, Idalberto. Introdução à teoria geral da administração.6 ed. Rio de Janeiro: Campus,2000.

GIL, Antônio Carlos. Gestão de pessoas: enfoque nos papéis profissionais. São Paulo: Atlas, 2001.

LAKATOS, E. M.; MARCONI, M. A. Técnicas de pesquisa : planejamento e execução de pesquisas, amostragens e técnicas de pesquisa, elaboração, análise e interpretação de dados. 1 ed. São Paulo: Atlas,1985.

NASSAR, Paulo. Comunicação interna: a força das empresas.V.1.São Paulo: Aberje.2003.

PIMENTA, M. A. Comunicação Empresarial. 3 ed. Campinas/SP: Editora Alínea, 2002.

TORQUATO, Gaudência. Tratado de Comunicação Organizacional e Política. São Paulo: Cengage Learning, 2002.

VIGNERON, Jacques. Comunicação Interna: Além das mídias. Líbero, Vol. 4, № 7, 2001. COMUNICAÇÃO INTERNA ALÉM DAS MÍDIAS. Disponível em: $<$ http://tupi.fisica.ufmg.br/ michel/docs/Artigos e textos/Ciencia da informacao/006\%20\%20Comunica\%E7\%E30\%20interna\%20-\%20al\%E9m\%20das\%20m\%EDdias.pdf>. Acessado em 26 de jun de 2013. 
A importância da comunicação Interna nas empresas. Disponível em:

$<$ http://www.sebraemais.com.br/noticias-midia/a-importancia-da-comunicacao-interna-nasempresas $>$. Acessado em 26 de jun de 2013.

Premio Aberje, o reconhecimento de uma boa comunicação! Disponível em:

<http://muitoalemdoguardanapo.wordpress.com/tag/case>. Acessado em 27 de jun de 2013.

Sala de Imprensa - Petrobras. Disponível em:

http://www.br.com.br/wps/portal/portalconteudo/acompanhia/saladeimprensa/>. Acessado em 27 de jun de 2013.

Campanha Interna da Petrobras Distribuidora Conquista Prêmio Aberje De 2011. Disponível em: $<$ http://www.comunicacaocomfuncionario.com.br/2012/02/23/campanha-interna-da-petrobrasdistribuidora-conquista-premio-aberje-de-2011/>. Acessado em 26 de jun de 2013.

Prêmio Aberje. Disponível em: <http://www.premioaberje.com.br/sobre-o-premio-aberje.asp $>$. Acessado em 26 de jun de 2013. 